\title{
Technology and Privacy, Internet Effects on Privacy
}

\author{
Eriola Cakrani \\ Phd Student \\ University "Ismail Qemali” Vlora, Albania \\ Department of Law \\ Tel: 0355692642891; eriol_hoxha@yahoo.it
}

Doi:10.5901/mjss.2013.v4n9p279

\section{Abstract}

\begin{abstract}
Technology is changing the world we are living in, but we should be concerned about our privacy for every new technological development. Rapid developments and globalization have brought new challenges towards personal data protection. Technology affects on every aspect of our life. So whenever we navigate in internet, make a phone call or use different technology tools our privacy becomes vulnerable because technological developments have not only positive sides but also negative ones. These activities, effecting directly or indirectly, influence and expose privacy related aspects of the life of persons. Scientific and technological progress, especially when it is related to information processing and communication of personal data cannot stand independent from the right and the standards that regulate the private life. The sector with the greatest impact on the lives of people is the internet and consequently this is a sector that requires a stronger legal regulation. The Protection of personal data is recognized as an autonomous fundamental right in the legally binding EU Charter of Fundamental Rights, but the technology develops and that is what the legislation should do too. This paper will focus on the coverage of the current situation in this domain and will aim at providing answers to some key questions such as: Which are the main challenges resulting from the rapid growth of technology? What should be the ratio privacy - technology?
\end{abstract}

Keywords: issues, social networks, European Union legal framework.

\section{Introduction}

What we could say without doubt is that the current developments in technology, the speed of their spread, the enormous capacity information storage are one of the most "critical"(weaknesses) moments in storage citizens` personal data. These developments are so rapid and apparently current that affect everyone.

Protection of personal data in relation to current developments in technology, is one of the subtle challenges of the global information society in which we live. There is no doubt that the proliferation of numerous activities within the use of information technology (e.g. electronic trade) use of new forms of communication, Internet access through Wi-Fi, present difficulties increasingly large and increased for legal adjustments as appropriate.

Young people are those who embrace faster these changes of technology, making them part of their life. The possibility of using new technology tools is definitely an expression of the position of the steps in the fields of science, but on the other hand these changes cannot avoid being associated with their negative aspects. It is the facing of these negative aspects what is considered one of the major challenges today. The use of technology in the wrong way and the wrong people (because the law authorizes people to process them, but they may fall prey to different hackers) violates human rights and the protection of personal data as a component of themselves. The personal data are considered as a one of the most important rights in the context of these developments, it is also associated with the need for a complete legal framework. In this context rapid changes in technology are often not accompanied by the same changes to legislation creating gaps in certain moments. This is the negative aspect of the changes of technology.

Among other continuous process of intertwining of new forms of communication has also brought new challenges in the processing of personal data. Thereby it is required the constant attention to users technologies protecting the privacy of potential danger.

The way this data is used from different commercial operators leads to the need for better means of protection of personal data.

Often people use their personal camera for entertainment purposes or the cultural ones transmitting images in which other people can also be part. What can infringe private life is not their holding in "safe" places, but their distribution in the third persons, online or other without the consent of those persons. This does not include journalists 
who do not require authorization for the publication of these pictures as serving a public interest, as may be the publication of pictures for public figures.

The legislation must be adapted to developments in the markets and technologies for electronic communications services in order to provide an equal level of protection of personal data and privacy for users of publicly available electronic communications services, regardless of the technologies used.

\title{
2. Relationship between privacy and Data Protection
}

The right to respect private and family life is part of the fundamental rights of the individual, and as such is guaranteed in all instruments and documents relating to human rights.

European Convention of Human Rights ("ECHR"), Article 8, states that:

\begin{abstract}
Everyone has the right to respect for his private and family life, his residence and his correspondence. No interference by a public authority in the exercise of this right except when intervention is in accordance with the law and when it is necessary for a democratic society in the interests of national security, public safety or the economic well-being of the country, the prevention of disorder or crime the protection of health or morals or for the protection of the rights and freedoms of others. "
\end{abstract}

As shown in the meaning of the first paragraph of Article 8, the notion of privacy is broad and can not be defined in an exhaustive way. ${ }^{1}$ Private life is considered, perhaps, as one of the concepts of human rights more difficult to define. Furthermore, every country in the world has incorporated the concept of privacy in its constitution. In fact, definitions vary, since we are dealing with a notion which has been expanding continuously, even through practice (case law) of the European Court of Human Rights ("ECHR").

In the notion of privacy would be included even physical and psychological integrity of a person. This notion implies not only the right to life at will and without the control of others, but also, to some extent, the right of connecting and keeping in touch with others - mainly in the sphere of emotions - in order to develop and realize thrown personality2.

In certain circumstances, by this right could take advantage even legal persons, who may require observance of goodwill, their headquarters, representations or environments in which operate ${ }^{3}$

It cannot be excluded from the concept of private life even the exercise of professional activity dealing with business, trade, etc.. Such a conclusion has reached the ECHR, as in the case "Niemietz $v$ Germany," cautions that most people develop their contacts, namely in the professional life 4 .

Warranty of this article is the right of everyone to seek recognition of it as harmed due to violation of Article 8 , in cases of collection and storage of the data by the authorities on their private lives ${ }^{5}$. In the case of "Rotaru v. Romania," the European Court of Human Rights, in its decision underlines that fall within the limits of the concept of "privacy" for purposes of this section, information on the life of the individual, on their education, on political activity, on conviction, if these are systematically collected and stored in folders by state officials.

It constitutes an interference in the exercise of the right to respect for private life e.g. collection, storage and disclosure of information on the private life of the individual, secured by way of tapping the telephone and postal communications control ${ }^{6}$. It is considered as interference even asking to determine the identity and then recording personal data. In the decision "Leander v. Sweden," the Strasbourg Court held that it constituted interference with the right to respect for private life preservation, discovery, along with the refusal to allow Leander for eventual correction of data, containing information of a private character, which were in the secret police records, (judgment of 26/03/1987, A.116).

Article 8 of the ECHR, cannot be interpreted in such a way that leads to the conclusion that only refers to measures that authorities use directly to a specific person and which constitute an attack on his/her private life or family. It also includes indirect interventions, which are the inevitable result of the actions that have affected specific persons. For example, loud noise from the surroundings, as for example, the airport can affect the good humor of the individual

\footnotetext{
1 Decision "Botta against Italy", dated on. 24.02.1998, par. 32

2 Decision "Stes Colas Est and others against France", dated on 16.04.2002, Appeal no. 37971/97.

${ }^{3}$ Decision "Niemietz against Germany", dated on 16.12.1992, A.251-B, par. 29.

4 Decision "Botta against Italisë", dated on 24.02.1998, par 35.

5 Decision "Klass and others against Germany ", dt. 06.09.1978, A.28.

${ }^{6}$ Decision of 16.07 .1986
} 
and thus be a concern for privacy, or to prevent the use of apartment?

While in another decision the European Court of Human Rights found that, as a direct result of the lack of such information on the right to respect for private and family life, the residents were not informed of the risk that brought pollution factory near where they lived. ${ }^{8}$

The right to privacy is strengthened by including in the catalog of human rights and fundamental freedoms, ensuring that the treatment of personal rights is consistent with these rights and fundamental freedoms in accordance with the dignity of the person concerned.

The right to privacy should be understood as a guarantee for the treatment of information or data to any other person (whether a physical person or legal one), who should come into line with dignified handling of personal and fundamental rights. ${ }^{9}$

\section{Legal guarantees for the protection of personal data in the context of developments in technology}

\subsection{Private life and electronic communications directive}

Directive on privacy and electronic communications is based on the same principles and guidelines for the protection of personal data. The Directive was adopted in 1997 (i.e. about two years after Directive 95/46) and was replaced in 2002 by an updated version: Directive 2002/58 on privacy and electronic communications.

Its purpose was to arrange and cover the part that was not covered by this Directive for Personal Data Protection Directive 95/46, (due to the rapid development of technology), such as entering invoices, marketing activities etc... Directive of 2002 reflects developments in markets and technology for electronic communication services, such as the Internet, in this way it is achieved the expected manner ensuring equal treatment for the protection of personal data and privacy, regardless of the form of technology used.

Directive was part of a five pacts and directives aimed at reforming the existing structure for electronic communication in the community. Above all, one of the goals was to create rules to ensure equivalent methods, independent of the technical means by which they spread. It served the purpose that customers and users of their data, regardless of the technology used or the type of service offered, to be ensured the same level of protection.

\subsection{Transfer of personal data}

In connection with the transfer of personal data several instruments have been processed in the European Union Directive 95/46/EC of the European Parliament and the Council, dated on 24th October 1995 "On the protection of individuals with regard to the processing of personal data and the movement of free movement of such data "and 2002/58/KE Directive of the European Parliament and the Council, dated on 12th July 2002," in regard to the processing of personal data and protection of privacy in the electronic communications sector "(Directive on privacy and electronic communications).

\subsection{Transfer of data}

In Europe it became worrying the transfer of data in the early 90s. In response to this pressure and enlargement of the community, it was unnecessary the re-treatment of personal data. In the 90 s the Commission (EU) adopted a package of measures which were able to provide a broad support for the protection of personal data. These were developed in order to harmanize the internal measures taken in this field. The key element was the suggestion to structure a directive, which would have two main goals in mind:

- ensure the protection of human rights and fundamental freedoms and in particular the respect of private life together with respect to the treatment of personal data,

- remove the limits on data transfer through community countries.

The need for the adoption of this Directive is dictated by such factors, as the current development of information society in which we live, the globalization of markets. Areas in which new instruments operating in the information and communication technology are increasingly simplifing the transfer of personal data among digital markets, in which the

\footnotetext{
${ }^{7}$ Guerra and others against Italy , par. 60

${ }^{8}$ Alessandro Del Ninno, La tutela dei dati personali, Padova 2006, CEDAM, pg. 4

${ }^{9}$ Decision of EU, NO. 520, dated on 26.07.2000
} 
very meaning of territoriality has been questioned due to the development of new forms of communication. Seen in this regard besides ensuring free flow of information must also be guaranteed circulation by the Directive.

Directive 95/46/EC explicitly handles data transfer right to third countries, allowing data transfer to these countries only in those cases when are guaranteed the conditions for their treatment.

On the Albanian lawmakers remains to be done fulfillment of our legal framework in accordance with this Directive, because we are still far from its regulations, in order for the law to provide guarantees for data handling during the transfer, to the extent and manner set out in the Directive.

EU Member States in accordance with Directive 95/46 have adopted the Safe Harbour agreement. Safe Harbour ${ }^{10}$ Agreement relating to the transfer of personal data to the United States of America ${ }^{11}$.

\subsection{Data transfer in non-member states of the European Union}

In regulation 45/2001 of the European Parliament and the Council are set rules regarding the processing of personal data and their transfer within the Community institutions and bodies. There are three different articles that regulate the transfer of data (Articles 7, 8 and 9). Article 8 defines the way data transfer within the Community institutions. But what happens if the data will be transferred to countries outside the Community?

In cases when data is transferred to countries which are not members of the European Union, perhaps it would be necessary to take measures if the specific level of data protection in third countries is inadequate compared to that prepared by the European law. Without regulating such high standards of data protection, set by these guidelines, should be placed rapidly by providing data to easily move around international network.

"The basic principle of data is that personal data may only be transferred to countries outside the EU that guarantee an adequate level of protection. Analysis of laws for data protection and dialogues with the European Union, with the most important members of the trade, is in a way in order to decide which state provides adequate protection.

When a non-member state of the European Union does not guarantee an adequate level of protection, the guidelines require the blocking of specific transfers. Member States shall inform the Commission of any blockage of ways and this community starts a procedure to ensure that each member state decision to block a particular transfer is justified, then the conditions for jam (not the same conditions with those that require community rates during treatment data).

\section{Conclusions}

The right to a private life is affirmed in all international instruments on human rights and basic human liberties. It presents as one of its elements the protection and handling of personal data by allowing their use only in terms of necessity and mass not greater than necessary.

So, the right to protect personal data expands privacy protection, but it is extended beyond it. Protection of personal data serves in order to ensure respect for fundamental rights and in particular (but not only) the right of the data subject's life related to his / her privacy. Personal data subjects are being more and more into question because of developments in technology, that's why there is a need to enjoy special attention. They are found in numerous international guarantees.

A very important aspect is the rapport that is created between the "crash" of rights, the right to information and the right to private life. The right to information on the one hand and the right to a private life on the other hand, are basic rights guaranteed as such in all instruments for human rights. The Right to information (Article $12 \mathrm{ECHR}$ ) and the right to a private life (Article $8 \mathrm{ECHR}$ ) are considered as rights which by their importance serve for the construction of a democratic state. They are widely interpreted by the ECHR and the case when it comes to "clash" between them. It is worth noting that case-by-case assessment of the birth of the "crash".

The right to privacy may sometimes conflict with freedom of expression and in particular freedom of the press and media. Therefore necessary to establish exceptions to the law of data protection, in order to achieve a balance between these differences, but equally and with the same rights and fundamental freedoms

The right to privacy may sometimes conflict with freedom of expression and in particular freedom of the press and

\footnotetext{
${ }^{10}$ Despite the existence of the Safe Harbour agreement, the personal data of European citizens who are traveling to the U.S., though it may be sensitive ones, for example. race, religious beliefs, must be made known to those authorities of these countries which 15 minutes before landing, without the prior consent of the subject. This part of the fight against terrorism, but infringing personal data.

${ }^{11}$ Portrait de Riwa, en ligne http://www.andaman.org/BOOK/chapter13/text13.htm
} 
media. Therefore it is necessary to establish exceptions to the law of data protection, in order to achieve a balance among these differences, but equally and with the same rights and fundamental freedoms

Practice shows that cases of violation of the right to personal data protection are put on the agenda, and every day more and more need is felt for a refinement of practice. In this regard, the European Court of Human Rights and the Court of Justice of the EU have a key role.

\section{References}

Marek Antoni Nowicki About European Convention, 2003.

Alessandro Del Ninno, La tutela dei dati personale, CEDAM, Padova, 2006

Temistocle Martines "DIRITTO Costitucionale" Giufree Editore 1997.

For a European public order. Selected decisions of the European Court of Human Rights, Tirana 2001.

Universal Declaration of Human Rights.

European Convention of Human Rights.

Convention on the protection of individuals with regard to the automated treatment of data of a personal nature (Strasbourg, 28 January 1981).

Order 1049/2001, for public access to documents.

Directive 95/46/EC of the European Parliament and the Council, dated on 24 October 1995, "On the protection of individuals with regard to the processing of personal data and the free movement of such data ".

Directive 2002/58/EC of the European Parliament and the Council, dated on 12 July 2002, "In regard to the processing of personal data and protection of privacy in the electronic communications sector."

Progress Report of the Commission of the European Communities, Brussels, 08.11.2006

Progress Report of the Commission of the European Communities, Brussels, 06.11.2007

\section{Decisions of the European Court of Human Rights}

The decision "Costello-Roberts v. the United Kingdom", dated on 03.25.1993.

The decision "Botta v. Italy", dated on 24.02.1998.

The decision "stest Colas Est and Others v. France", dated on 16.04.2002.

The decision "Niemietz v Germany", dated on 16.12.1992.

The decision "Botta v. Italy", dated on 24.02.1998.

The decision "Germany Klass and others," no. 06.09.1978.

$Z \mathrm{v}$. Finland, judgment of 25 February 1997

Rotaru v. Romania, judgment dated on 04.05.2000.

Murray v. United Kingdom, judgment dated on 28.10.1994.

Leander v. Sweden, judgment of 26.03.1987

Gaskin v. the United Kingdom, judgment of dated on 07.071989

\section{Decisions of the European Court of Justice of the EU}

Lindqvist decision dated on 06.11.2003

Decision Osterreichischer Rundfunk dated on 20.052003 